\title{
DEVELOPING COMMUNICATIVE COMPETENCE IN L2 TERTIARY LEVEL STUDENTS: REMARKS ON CULTURALLY RESPONSIVE TEACHING
}

\author{
JERZY ZYBERT, IGA LEHMAN
}

\begin{abstract}
Semiotic links exist among communication, culture, teaching, and learning and this has important implications for implementing culturally responsive teaching. The present paper provides some arguments in favour of creating culturally sensitive classrooms where students have an opportunity to acquire a broader cultural awareness which helps them to develop their intercultural communicative competence.
\end{abstract}

Key words: L2 teaching, L2 learning, academic communication, cultural values, identity

\section{Introduction}

Semiotic links exist among communication, culture, teaching, and learning and this has important implications for implementing culturally responsible teaching. This is because "what we talk about; how we talk about it; what we see, attend to, or ignore; how we think; and how we think about are influenced by our culture...[and] help to shape, define, and perpetuate our culture" (cf. Porter and Samovar, 1991: 21). Making essentially the same point, Bruner argues that "learning and thinking are always situated in a cultural setting and always dependent upon the utilization of cultural resources" (cf. Bruner, 1996: 4). Cultural competence provides the tools to pursue the search for meaning in communication and thereby enables our understanding of others. As a result, second language (L2) communicative competence is not possible without L2 cultural competence, and L2 teaching and learning needs to reflect this relationship. 
The university is often a setting in which students first encounter a community comprising people, including peer students and instructors, from a variety of countries and ethnic groups. With such a diverse community of learners and teachers, communication in the classroom can be inspiring and yet problematic. At times, the best efforts of instructors to reach their students are unsuccessful and this is often because students in multicultural classrooms lack experience of the teaching methods employed or the communication style used by the academic instructors.

Since culture profoundly influences how we learn and teach, it is a key factor in determining how students and teachers interact to establish an effective teaching and learning environment. Educational systems are developed based on the rhetorical conventions practiced by individual societies. In a culturally diverse classroom, students and teachers may disagree on appropriate ways of engaging in academic discourse and activities, or whether to get engaged at all. Communication norms, such as directness versus indirectness, formality versus informality or nonverbal ways of conveying messages are all culturally constituted. Therefore, although the culturally diverse academic classroom offers a variety of benefits to students and instructors, both need to make significant efforts to understand how cultural differences may influence communication and ultimately the teaching and learning processes. This article has been written with this purpose in mind.

Despite the all-pervasive presence of culture in any educational setting, we cannot investigate all the aspects of culture that affect classroom communication. We therefore need to focus on those cultural elements which we consider the key to an effective teaching/learning process. Therefore, first we need to look at some theoretical and practical considerations related to L2 acquisition. Then we will examine the major cultural values that influence academic communication. The final issue we discuss pertains to how value differences influence teaching and learning styles across cultures.

\section{Theoretical and practical considerations}

Both foreign language teaching practice and observation of students' communicative performance in language classrooms testify to the claim that language learning is significantly enhanced if it is combined with learning target culture. Students of English with culturally diverse backgrounds usually do not realize what communicative norms are expected in Anglo-American academic discourse conventions. For this reason teaching culture becomes necessary if students are to attain adequate and proper communicative competence. Integrating cultural dimensions will enable teachers to fulfil their responsibility for extending students' worldviews and to achieve meaningful educational purposes. In the quest for better and more effective ways of foreign language teaching (FLT) large numbers of methodological proposals have been advanced in the form of approaches and methods. Some of them 
became widely popular, whereas others proved to be of little pedagogical value and quickly disappeared from language classrooms. In consequence, established ways of teaching languages were substituted for innovative, more modern approaches that promised new perspectives in language education.

Among the issues that those approaches raised there was the question of language learning goals. It was postulated already well over a decade ago that language teachers need to know "what kind of language knowledge or ability constitutes the goals that learners are to achieve at the end of the course", and (...), ,what kind of student activity is effective as the means to that end" (cf. Widdowson, 2004: 379). To respond to such queries language pedagogy has drawn substantially from various disciplines such as psychology, cognitive linguistics and communication and SLA studies. English language teaching (ELT) has also significantly benefited from the acknowledgement of the view that language and culture are inseparable. In consequence, it has been accepted that if students of a foreign language are to communicate effectively, they must develop not only language skills but also, simultaneously, gain a good knowledge of the target language communities and their culture.

The general recognition of a strong link between language and culture has resulted in identifying the two phenomena as synonymous; contentions such as: "language and culture are inseparable", "language is culture", or "culture is language" are frequently found in the literature (e.g. this position is taken by Kramsch, 1993). The straight connection of language with culture or, rather, their inseparability, has been widely recognized nowadays. This link is often manifested in the current interest of researchers and in the substantial numbers of relevant publications. Language as a social phenomenon is strongly bound up with the cultural heritage of its native speakers and is marked by their characteristic verbal behaviours. Therefore language learning requires that students develop familiarity with the target culture. This will involve helping learners to develop a new identity as second language users and will ultimately lead to changes in them as social individuals.

Most theories of communication point out that cultural competence not only determines the efficiency of communication but also influences various aspects of verbal interactions between interlocutors whose mother tongues are different. Culture imposes a variety of communicative codes and norms on language users and their communicative behaviour, whether verbal or non-verbal, differs due to cultural differences (cf. Samovar and Porter, 2004: 202).

\section{Cultural values and identity issues that influence academic communication}

Those who have travelled widely, lived in different countries and states, worked with people of various ethnic backgrounds, nationalities, and religions can easily appreciate the difficulties that students encounter when navigating a new linguistic 
and cultural territory. They need guidance in becoming acquainted with AngloAmerican norms that govern verbal communication. Consequently, it is for the academic instructor to make those cultural standards explicit and to help students narrow the cultural divide. One of the ways to remedy communicative problems is by implementing culturally responsive teaching as is exercised in America where it traditionally promotes achieving meaningful educational outcomes. The culturally responsive classroom, also referred to as an inclusive classroom, is a space where all the voices are sought out and welcome, whereas the participants feel free to challenge or support other people's perspectives on different topics, and are not uncomfortable taking necessary risks for real communication to occur. Clearly, multiculturalism is one of the most appealing aspects of language teaching. In teaching multicultural groups of students the teacher can only succeed and attain desired goals if she/he manages not only to establish a good rapport with the group but, first of all, to bridge cultural gaps between individual students. Observation of the process of integrating a multi-lingual group shows that the major problems lie in students' different conceptions of self and identity and variations in communication styles.

Human identity it can be investigated in three different perspectives:

- cultural (related to certain values, beliefs and norms shaped by traditions, cultural heritage, language, religion, and thinking patterns typical of a particular culture),

- social (associated with the sense of belonging to a specific social group that a person identifies with because of similarities in age, gender, work, religion or ideology),

- personal (related to the unique qualities a person possesses that make her/him different from other members of the group).

The cultural dimension referred to as individualistic/collectivist seems to best describe the relationship between culture and the processes underlying identity construction. According to Hofstede (1980), individualism/collectivism is the degree to which individuals are supposed to look after themselves or remain integrated into groups, usually based around the family. For example, Anglo-American culture/society promotes achievement, growth and personal fulfillment. Puritans and the Founding Fathers provided a solid basis for creating a culture that encourages hard work, commitment, and self-reliance. Although Americans exhibit a community spirit in terms of working together for the benefit of the community, the predominant national qualities are individuality and independence. On the other hand, in the case of central and eastern European cultures, which are small and rather homogeneous, collective thinking tends to dominate over individual thinking. Vassileva (2000) argues that this is evident in these cultures' efforts to preserve their cultural identity and independence. Conversely, Middle Eastern, East Asian and African sense of identity and self-awareness are shaped by interpersonal relations and mani- 
fest collectivistic cultural orientation. The strong sense of belonging to a community makes people feel responsible for their families and friends. The success of the group ensures the well-being of an individual, so that by considering the needs and feelings of others, one actually protects oneself. To illustrate this interdependence Pillay discusses a Pan-African term ubuntu that means "humanness or personhood". A literal translation of this expression is: "A person being a person through other persons" (2006: 37).

The discrepancy between individualistic and collectivistic attitudes can be observed in the English language classroom where instruction is normally governed by Anglo-American cultural behaviours and beliefs. Students from collectivistic countries do not attach the same importance to academic honesty and discipline as more individualistic societies would do. Conflicts can occur between the teacher and students from collectivistic cultures who sometimes challenge the authority by breaking the policies related to academic honesty and for example, cheat in tests. They are eager to collaborate with one another regardless of the situation and circumstances. Being loyal to friends is paramount even though it means violating university principles and putting their own academic career at risk. Middle Eastern students tend to see homework as optional, or ask for special consideration to miss class or come late to classes and hand in homework assignments late. Instances of their collectivist sense of loyalty and generosity in interpersonal relations can be observed in the classroom. For example, if there is a student in a class who falls behind and is unable to follow a lecture, she/he is promptly assisted by classmates in clarifying problems.

Since relationships in collectivistic cultures are of vital importance, once a lecturer wins the students' confidence and respect, they often approach her/him willing to chat and joke. One way of establishing a good rapport with Middle Eastern students is to be open to negotiations on pedagogical issues. Personal experience with Arab students demonstrates that bargaining with them, e.g. about what to do for homework, can result in the successful learning outcomes. At first it seemed they were attempting to undermine the teacher's authority, but it soon turned out that negotiation is part of their culture and a way to come to terms on an issue and build a relationship of mutual understanding between the student and teacher.

During both formal (classroom situations) and informal (casual conversations) encounters with Middle Eastern students tend to be very interactive and verbose. Therefore, it is a huge challenge for an instructor to keep them concentrated on one task. To make sure they stay focused, it is best to use a variety of individual, pair and group activities. On the whole, Middle Eastern students are usually very friendly, out-going and willing to take risks in speaking/listening activities. If the teacher can channel their energy in the right direction, she/he can have a dynamic, studentoriented environment. These students enjoy working in multi-lingual groups and engaging with others because relationships are important. However, sometimes they 
have problems in recognizing the limits of how long it is acceptable to joke in class and it can be hard to get them back on task, even after a small digression. Their difficulties with concentration on one activity at a time may also result from an intense desire to communicate verbally. However, while struggling to limit their urge to talk lots of humorous situations occur. For example, when asked why he was late to class a Turkish student responded: "My professor, since I can't talk enough in class I was out in the hall talking to a coffee machine."

Another important source of intercultural differences that matter in academic communication is the different time orientation present in a multi-cultural classroom. This cultural value has been referred to by E. Hall (1959) as a monochronicpolychronic time perspective. Teaching practice shows that the qualities of being polychronic apply to the majority of the inhabitants of the Middle East, Asia and Africa, whereas North European and North American societies adhere to a monochronic orientation. Central and eastern European societies exhibit behaviours which place them somewhere in the middle of the monochronic/polychronic continuum.

To a polychron time is continuous with no particular structure. It is cyclical; things happen in cycles such as the cycle of the seasons or rebirth through reincarnation. Time reaches areas beyond lifetime and human comprehension. To people operating in this sequential time perspective time is not a finite concept because life events are cyclical, integrated within past, present and future.

Monochrons see time as divided into fixed periods, seconds, minutes, hours, days, weeks, and so on, temporal blocks that can be organized, quantified and scheduled. Time is fast, present and short-term future oriented and therefore also a valuable 'commodity'. It is a point along a timeline which is tangible and can be saved, spent, wasted or gained. Expressions such as "Never put off till tomorrow what you can do today", "Seize the moment" (carpe diem) or "Don't waste time" emphasize the fact that if time is lost, it cannot be recovered. Therefore, monochronic societies organize their lifestyles around the clock and favour youth, energy and vitality. All the tasks, activities are carefully planned and scheduled and defined within specified boundaries. American students are hardly ever late to class and never question the consequences of being tardy described in the institutions regulations. In contrast, Middle Eastern students struggle to understand that time is not flexible. The attendance policy (coming to class on time in particular) is difficult for them to obey. This requirement of being only makes sense to them at the end of the semester when they see how much tardiness has affected their final grades and at this point they are usually confused and feel a deep sense of injustice.

The fact that culture determines certain patterns of thinking and behaviour is also reflected in different communication styles, which can be observed in L2 students' oral and written academic discourse. For example, westerners are perceived as individualistic, rationalistic, analytical, and competitive, whereas easterners appear more communitarian, cooperative, contemplative, self-reflective, and inward 
looking. These cultural attitudes and behaviours are reflected in the rhetoric and logic of Western and Eastern languages, as observed by Hall who divided cultures into low-context and high-context (E. Hall 1959).

High context cultures favour nonverbal communication where meaning is contained in context and behaviour rather than in words. People use certain shared nonverbal codes to get a message across. For example, Turkish students demonstrate their respect for a teacher by rising from their chairs upon her/his entrance into a room. It is an acknowledgement of the teacher's status and leading position in the class. Low context communication focuses on the exchange of words with a limited use of contextual cues. The low context approach values explicit, overt messages and relies on literal meanings of words. The purpose of the communication process is to get a yesno response, to assign responsibility or blame, to get the facts. "Just the facts, ma'am" was a common feedback a Polish teacher received in the U.S. when she tried to use her Polish, more context-dependent logic, to explain different issues.

The consequences of the differences between high and low-context communication styles reveal themselves in the way speakers of various languages organize and communicate their thoughts. The most significant difference in the organizational structure of an expression concerns languages that are speaker-oriented versus those that are listener-oriented. In speaker-responsible languages, which are typical of low context societies, a speaker conveys specific information directly and explicitly using the literal meaning of words. The prior knowledge of the speaker's intent is not necessary. High context communicators hold the listener responsible for constructing the meaning based on the background knowledge the speaker shares with the listener. The interlocutors rely heavily on context to communicate messages and indicate indirectly the subject being discussed.

While teaching L2 students substantial information can be obtained as to practical outcomes of language use with respect to their organization of ideas. Even if they are linguistically competent, there seems to be a lack of logical order in their oral presentations and this results from the nonlinear structure of their native languages where contextual cues are prior to a thesis statement. Having to evaluate such students' work according to the Anglo-American requirements for speech and paper organization requires the instructor to focus on things like, the clarity of thesis, their arbitrary division between main points and sub-points, poor transitioning between ideas and irrelevant digressions.

\section{Value differences in teaching and learning styles across cultures}

Teaching and learning styles reflect our preferences for the ways to internalize and understand ideas and concepts. These ways are both idiosyncratic and constituted by the dominant teaching and learning approaches that our society has sanctioned 
and used to develop and implement its educational system. In the multicultural classroom, teaching methods and ways of communicating are not always in line with the approach of learning to which most students may be accustomed in their first culture. Hofstede's model of value differences in teaching and learning outlined in Table 1 helps not only to become aware of these differences but also to formulate questions about our own cultural values and expectations in relation to teaching and learning in a culturally diverse classroom.

Table 1. Value Differences in Teaching and Learning (source: Hofstede, 1986)

\begin{tabular}{|c|c|}
\hline $\begin{array}{l}\text { Collectivistic Societies (Arab countries, Arab, Mexico, } \\
\text { Portugal, Taiwan, Japan) }\end{array}$ & $\begin{array}{l}\text { Individualistic Societies (Great Britain, United States, } \\
\text { Norway, Germany, Spain, France) }\end{array}$ \\
\hline Young should learn; adults cannot accept student role. & One is never too old to learn. \\
\hline $\begin{array}{l}\text { Students will speak only when called upon by teacher; } \\
\text { harmony in learning situations should be maintained at } \\
\text { all times. }\end{array}$ & $\begin{array}{l}\text { Individual students will speak up in response to general } \\
\text { invitation of teacher. }\end{array}$ \\
\hline $\begin{array}{l}\text { Education is a way of gaining prestige, getting into higher } \\
\text { social class. }\end{array}$ & $\begin{array}{l}\text { Education is a way of improving economic worth and self- } \\
\text { respect based on ability and competence. }\end{array}$ \\
\hline $\begin{array}{l}\text { Teachers expected to give preferential treatment to some } \\
\text { students. }\end{array}$ & Teachers expected to be strictly impartial. \\
\hline $\begin{array}{l}\text { Small Power Distance Societies (Costa Rica, Sweden, } \\
\text { United States, Australia, Canada, Netherlands) }\end{array}$ & $\begin{array}{l}\text { Large Power Distance Societies (France, South Africa, } \\
\text { African countries, Arab countries, Japan, Korea, Thai- } \\
\text { land) }\end{array}$ \\
\hline $\begin{array}{l}\text { Teachers should respect independence of students. } \\
\text { Student-centered education. } \\
\text { Teacher expects students to find their own paths. } \\
\text { Students allowed to contradict teacher. } \\
\text { Effectiveness of learning related to amount of two-way } \\
\text { communication in class. } \\
\text { Outside class, teachers are treated as equals. }\end{array}$ & $\begin{array}{l}\text { Teacher merits the respect of students. } \\
\text { Teacher-centered education. } \\
\text { Students expect teacher to outline paths to follow. } \\
\text { Teacher is never contradicted. } \\
\text { Effectiveness of learning related to excellence of teacher. } \\
\text { Respect for teachers shown outside of class, they maintain } \\
\text { authority. }\end{array}$ \\
\hline $\begin{array}{l}\text { Weak Uncertainty Avoidance Societies (Canada, Hong } \\
\text { Kong, India, Sweden Philippines) }\end{array}$ & $\begin{array}{l}\text { Strong Uncertainty Avoidance (Japan, Greece, Peru, } \\
\text { Korea, Austria, Equador) }\end{array}$ \\
\hline $\begin{array}{l}\text { Students feel comfortable in unstructured learning situa- } \\
\text { tions. }\end{array}$ & $\begin{array}{l}\text { Students feel comfortable in unstructured learning situa- } \\
\text { tions (precise, objective, detailed assignments, strict } \\
\text { timetables). }\end{array}$ \\
\hline Teachers are allowed to say "I don't know." & Teachers expected to have all the answers. \\
\hline Good teacher uses plain language. & Good teacher uses academic language. \\
\hline $\begin{array}{l}\text { Students rewarded for innovative approaches to problem } \\
\text { solving }\end{array}$ & Students rewarded for accuracy in problem solving. \\
\hline $\begin{array}{l}\text { Feminine Societies (Sweden, Denmark, Costa Rica, } \\
\text { Chile, Spain, France, Finland) }\end{array}$ & $\begin{array}{l}\text { Masculine Societies (Jamaica, Austria, Mexico, Japan, } \\
\text { Ireland, United States, Australia, Venezuela) }\end{array}$ \\
\hline $\begin{array}{l}\text { Teachers avoid openly praising students. } \\
\text { Teachers use average students as the norm. } \\
\text { System rewards students' social adaptation. } \\
\text { Students admire friendliness in teachers. } \\
\text { Students try to behave modestly. } \\
\text { Male students may choose traditionally feminine academic } \\
\text { subjects. }\end{array}$ & $\begin{array}{l}\text { Teachers openly praise good students. } \\
\text { Teachers use best students as the norm. } \\
\text { System rewards students' academic performance. } \\
\text { Students admire brilliance in teachers. } \\
\text { Students try to make themselves visible. } \\
\text { Male students avoid traditional feminine subjects. }\end{array}$ \\
\hline
\end{tabular}




\section{Conclusions}

In this article we have outlined a culturally sensitive approach to teaching and learning. As with any other context of communication, the classroom is the place where communication occurs among many people. This contributes to the development of relationships which are the responsibility of all members of a classroom. Each day in the culturally diverse classroom, intercultural events take place, as instructors and students strive to teach and learn from one another. As teachers, this makes us consider our own role in the intercultural events we participate in each time we enter an academic classroom. What is happening communicatively to foster or hamper learning? What are the cultural aspects to the ways of explaining and understanding communication among students and instructors? What can we do to contribute to this cross-cultural understanding?

To conclude our remarks and reflections, it is important to mention that the present article is not based solely on didactic or methodological considerations but also on cultural considerations, founded on our practice and experience in teaching English as a foreign language, in mainly the speaking and writing skills, to both native and non-native students. It follows that teaching culturally diverse groups of students is a multidimensional endeavour. Most importantly, the achievement of meaningful educational objectives is not a matter of forcing students to accept and conform to Anglo-American socio-cultural standards and equipping them only with predetermind linguistic skills, but is rather the matter of acknowledging that the teaching process includes both cultural and linguistic dimensions.

\section{References}

Bruner, I. 1996. The culture of education. Cambridge, MA: Harvard University Press.

Hall, E. 1956. The silent language. Garden City, NY: Doubleday.

Hofstede, G.H. 1986. "Cultural differences in teaching and learning." International Journal of Intercultural Relations 10. 301-319.

Hofstede, G.H. 1980. Culture's consequences: international differences in work-related value. London and Beverly Hills, CA: Sage Publications.

Kramsch, C. 1993. Context and culture in language teaching. Oxford: Oxford University Press.

Pillay, V. 2006. "Culture. exploring the river". In LeBaron, M. and V. Pillay (eds.). Conflict across cultures: a unique experience of bridging differences. Boston: Intercultural Press. 25-56.

Porter, R.E. and L.A. Samovar. 1991. "Basic principles of intercultural communication". In: Samovar, L.A. and R.E. Porter. (eds.). Intercultural communication: a reader (6 ${ }^{\text {th }}$ edition). Belmont, CA: Wadsworth. $5-22$.

Widdowson, H. 2004. „The ownership of English.” TESOL Quarterly 2. 377-389.

Samovar, L.A. and R.E. Porter. 2004. Communication between cultures (4 $4^{\text {th }}$ edition). Boston: Wadsworth/ Thomson Learning.

Vassileva, I. 2000. Who is the author? A contrastive analysis of authorial presence in English, German, French, Russian and Bulgarian academic discourse. Sankt Augustin: Asgard. 